\title{
A IMPORTÂNCIA DOS INDICADORES DE DESEMPENHO EM UM PREPARATÓRIO PARA CONCURSOS PÚBLICOS - ESTUDO DE CASO: PROJETO PETROBRAS 2011.1
}

\section{ARTIGO ORIGINAL}

RODRIGUES, Hugo Martins Santos ${ }^{1}$, GANEFF, Camila², ALMEIDA, Jéssica Siqueira de $^{3}$, ROSSET, Aline Batalha ${ }^{4}$, GONÇALVES, Ana Lúcia Fraga Santana ${ }^{5}$, SILVA, Mônica Roberta ${ }^{6}$

RODRIGUES, Hugo Martins Santos. Et al. A importância dos indicadores de desempenho em um preparatório para concursos públicos - estudo de caso: projeto Petrobras 2011.1. Revista Científica Multidisciplinar Núcleo do Conhecimento. Ano 06, Ed. 07, Vol. 03, pp. 103-127. Julho de 2021. ISSN: 24480959, Link de acesso: https://www.nucleodoconhecimento.com.br/engenharia-deproducao/projeto-petrobras,

DOI: 10.32749/nucleodoconhecimento.com.br/engenharia-de-producao/projeto-petrobras

\section{RESUMO}

O presente artigo busca entender como os indicadores-chave de desempenho (Key Performance Indicators - $K P I)$ podem contribuir em um curso preparatório para concursos públicos. Tem como questão norteadora: "Como os indicadores de desempenho podem contribuir em um preparatório para concursos públicos?" Os

\footnotetext{
${ }^{1}$ Pós-graduação em Engenharia de Produção com Ênfase em Gestão Industrial - UERJ. Pós-graduação em Engenharia de Produção e Gerenciamento de Projetos - Faculdade UniBF. Bacharel em Engenharia de Produção - Cefet.

${ }^{2}$ Pós-graduação em Engenharia de Produção e Gerenciamento de Projetos -IBF. Pós-graduação em Engenharia da Qualidade e Responsabilidade Social - IBF. Bacharel em Engenharia de Produção - Cefet.

${ }^{3}$ MBA em Qualidade e Gestão de Processos - Universidade Católica de Petrópolis. Bacharel em Engenharia de Produção - ISE CENSA.

${ }^{4}$ Bacharel em Engenharia de Produção - Universidade Candido Mendes.

${ }^{5}$ Pós-graduação em Engenharia de Produção e Gerenciamento de Projetos - IBF. Bacharel em Engenharia de Produção - Universidade Veiga de Almeida.

${ }^{6}$ Orientadora. Mestrado em Administração de Empresas - Universidade Metodista de São Paulo. Pósgraduação em Gestão Empresarial - Universidade Metodista Bennett. Bacharel em Comunicação Social Universidade Estácio de Sá.
}

Disponível em: https://www.nucleodoconhecimento.com.br/engenharia-deproducao/projeto-petrobras 
indicadores escolhidos foram a eficiência, a eficácia e a efetividade e as suas respectivas aplicações. A abordagem utilizada foi um estudo qualitativo, baseado no estudo de caso único do "Projeto Petrobras 2011.1". Este projeto foi criado a partir da oferta de 15 vagas diretas para engenheiros de produção pela Petrobras em 30/06/2011 e contou com 6.554 candidatos, o que perfaz uma relação candidato/vaga de 436 candidatos para uma vaga e um período de 58 dias de preparação. Além dos KPI's, outras ferramentas foram utilizadas no desenvolvimento do referido projeto, tais como: benchmarking, banco de dados, planilhas eletrônicas, projeto com ciclo de vida iterativo, dentre outros. Os principais resultados obtidos foram a aprovação dos alunos, a conquista do $2^{\circ}$ lugar em portadores com deficiência (PCD) e o 4ํ lugar na ampla concorrência $(A C)$, além de uma apostila com 671 questões que nortearam o estudo das turmas subsequentes e uma nova metodologia de ensino. O trabalho trouxe como fator de inovação a aplicação dos conceitos de KPl's na área da educação e ensino, especificamente no ensino focado em concursos públicos no Brasil.

Palavras-chaves: Indicadores-chave de desempenho, Eficiência, Efetividade, Concurso público, Petrobras.

\section{INTRODUÇÃO}

Segundo a editora Folha Dirigida (2021), referência nacional na área de concursos públicos, o mercado brasileiro movimenta, cerca de, $\mathrm{R} \$ 50$ bilhões por ano e, com a atual crise financeira, aproximadamente, 14,7 milhões de pessoas estão desempregadas (IBGE, 2021), logo, chega-se a uma conclusão inevitável: o acirramento da concorrência.

A título de comparação, o nível de concorrência dos concursos da Polícia Rodoviária Federal (PRF) e da Polícia Federal (PF) com oferta de 1.500 vagas cada um, realizados em maio de 2021 tiveram, respectivamente, 304.330 inscritos (PRF: 202 candidatos/vaga) e 321.615 inscritos (PF: 214 candidatos/vaga), uma média de 208 
candidatos/vaga (CEBRASPE, 2021), logo, a quantidade de candidatos foi 208 vezes maior, em média, que o número de vagas.

Já o referido estudo de caso do artigo foca no preparatório para a prova da Petrobras de 2011.1 cujo respectivo edital ofertou 15 vagas para engenheiros de produção e contou com 6.554 candidatos (CESGRANRIO, 2011), o que perfaz uma relação de 436 candidatos/vaga, ou seja, o número de candidatos é 436 vezes maior, em média, que a quantidade de vagas ofertadas, representando um pouco mais que o dobro $(109,6 \%)$ da média da relação candidato/vaga dos concursos da PRF e PF.

Deming (2014) aponta que: "Não se gerencia o que não se mede, não se mede o que não se define, não se define o que não se entende, e não há sucesso no que não se gerencia", portanto, a medição é tão importante quanto à elaboração de um bom projeto.

Em pesquisa realizada pela Folha Dirigida, o mercado de concurso públicos em 2020 revelou as seguintes particularidades, demonstrando o panorama deste mercado: 
Figura 1: Mercado de Concursos Públicos em 2020

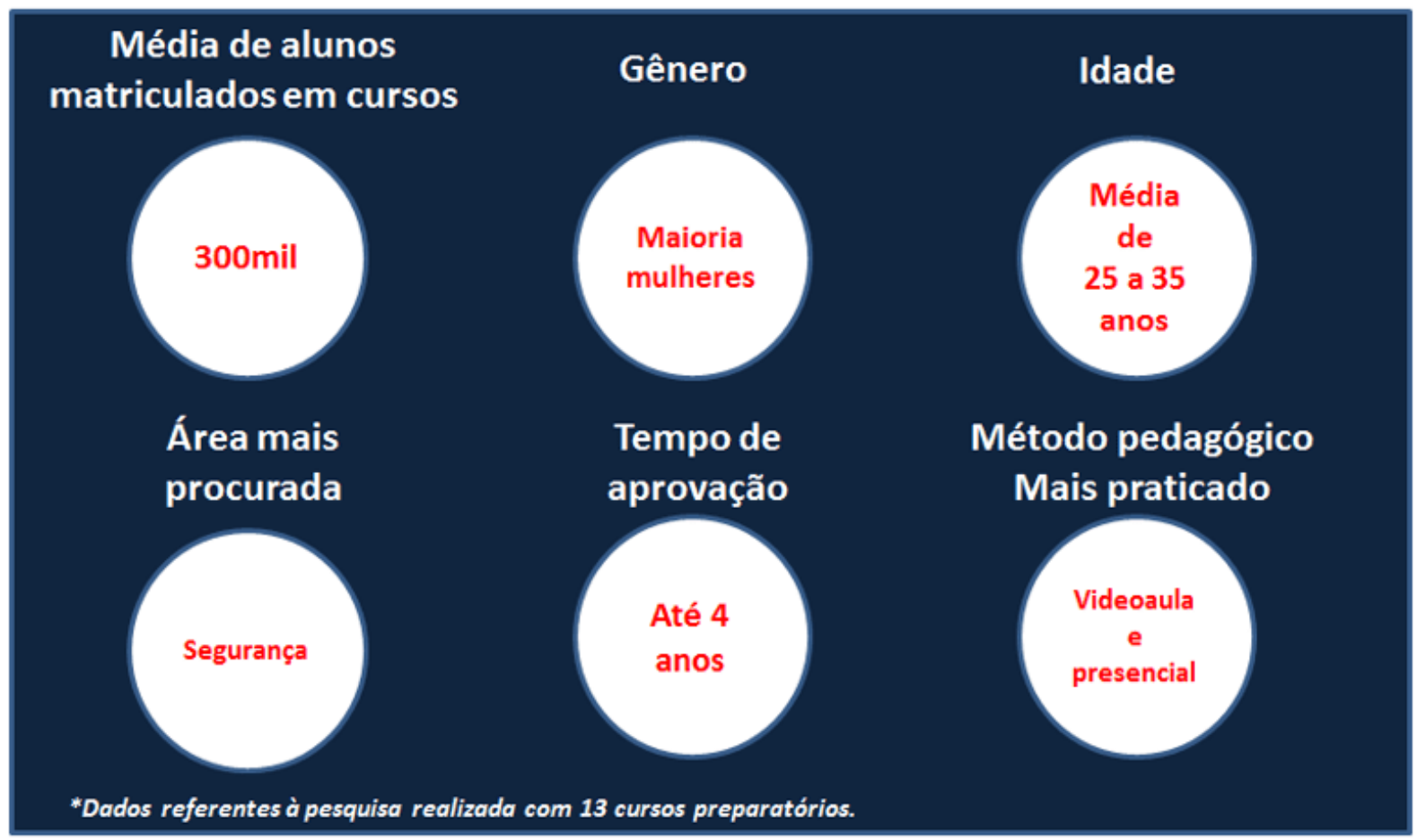

Fonte: Folha Dirigida (2021)

Diante do contexto apresentado, faz-se necessário um apoio educativo profissional aos candidatos no processo de qualificação para a prova da Petrobras 2011.1, nomeado "Projeto Petrobras 2011.1", porque um simples erro, nesta etapa, pode ser fator decisivo para a reprovação deles.

Assim, neste estudo de caso, é abordada a forma como os indicadores de desempenho e seus respectivos desdobramentos auxiliam na fluidez desse projeto não somente no número de aprovados no concurso que participavam do projeto, mas também no desenvolvimento qualitativo individual desse candidato.

O presente artigo consiste em um estudo de caso focado no Projeto Petrobras 2011.1, que consiste em qualificar os alunos de um curso preparatório para concursos públicos, Curso X, localizado na cidade do Rio de Janeiro, em um curto período de 58 dias, nas disciplinas de Administração da Produção, Planejamento Estratégico, Administração Geral e Gestão de Pessoas e Responsabilidade

Disponível em: https://www.nucleodoconhecimento.com.br/engenharia-deproducao/projeto-petrobras 
Socioambiental. Além disso, ele aborda como os indicadores-chave de desempenho, em inglês, key performance indicators (KPI), podem ser usados nesse contexto e os respectivos desdobramentos na preparação dos alunos a lograrem êxito em um setor altamente competitivo. A metodologia utilizada se deu por meio de estudo de caso, feito através de pesquisa de campo. Além disso foram feitas análise de dados do próprio curso, revisão aprofundada de bibliografias pertinentes ao tema e, no processo de elaboração do conteúdo, foram acrescidos gráficos e figuras para melhor elucidação das questões apresentadas.

Mediante o exposto, a pergunta de pesquisa a ser respondida foi definida: "Como os indicadores de desempenho podem contribuir em um preparatório para concursos públicos?"

\section{METODOLOGIA}

O presente trabalho apresenta-se por meio de um artigo científico que, segundo ABNT (2003, p.2), caracteriza-se por ser: "(...) parte de uma publicação com autoria declarada, que apresenta e discute ideias, métodos, técnicas, processos e resultados nas diversas áreas do conhecimento."

\subsection{MÉTODO}

Optou-se um por estudo qualitativo, a partir de uma metodologia de estudo de caso porque:

(...) um estudo de caso é uma investigação empírica que: (...) investiga um fenômeno contemporâneo dentro de seu contexto da vida real, especialmente quando (...) os limites entre o fenômeno e o contexto não estão claramente definidos. (...) Em outras palavras, você usaria o método de estudo de caso quando deliberadamente quisesse lidar com condições contextuais - acreditando que elas poderiam ser altamente pertinentes ao seu fenômeno de estudo (YIN, 2007, p. 32).

Por se tratar de uma metodologia própria de ensino, entende-se que a abordagem de estudo de caso único é a mais indicada porque a metodologia de ensino foi 
desenvolvida a partir das necessidades dos alunos e de seus pontos fracos, tais como: lentidão, falta de atenção, ambiguidade, falta de conhecimento, ansiedade, dentre outros.

A aluna Rafaela, citada como exemplo no decorrer do estudo, concedeu a permissão que seus dados fossem utilizados neste artigo. $O$ artigo em questão traz o conteúdo programático que foi exigido dos candidatos, as matérias que foram contempladas no projeto, o prazo de preparação e as ferramentas e indicadores de desempenho que foram empregados.

\subsection{FERRAMENTAS}

Dentre as diversas ferramentas de gestão existentes, optou-se por:

i. Banco de dados (BD) ("coleção de dados e informações que atendem às necessidades da empresa" - ARAÚJO, 2009) segmentado com questões com alto grau de dificuldade, escolhidas uma a uma pela professora orientadora, de acordo com a sua expertise na área. Foi usado o programa Microsoft pela facilidade de uso. A codificação adotada para as questões foi:

(BANCA/ENTIDADE/ANO/CARGO/ÁREA/DISCIPLINA/GRAU) $\mathrm{N}^{\circ}$ Corrente/ $\mathrm{N}^{\circ}$ Original, ex.:

(CESGRANRIO/PETROBRAS/2010/EPROD/APO/PCP/1) 01/21

- Áreas:

APO: Administração da Produção

.PEST: Planejamento Estratégico

. ADG: Administração Geral

. GRS: Gestão de Pessoas e Responsabilidade Socioambiental 
- Graus de dificuldade:

1: Fácil

2: Intermediário

. 3: Difícil

- Disciplinas/Área:

DES: Indicadores de Desempenho (ADG)

. MAN: Gestão da Manutenção (APO)

. PCP: Planejamento e Controle da Produção (APO)

. PE: Planejamento Estratégico (PEST)

. QLDE: Gestão da Qualidade (APO)

. RSE: Responsabilidade Social (GRS)

. RSA: Responsabilidade Ambiental (GRS)

. GPE: Gestão de Pessoas (GRS)

. SI\&TI: Sistema de Informação (APO)

Há cerca de 60 disciplinas cadastradas.

ii. Benchmarking ("comparação das melhores práticas" - SLACK et al, 2009) dos melhores alunos em determinadas disciplinas. O concurso Petrobras 2010.2 teve como maior nota $43 / 50$, isto é, o $1^{\circ}$ lugar acertou $86 \%$ das questões específicas (CESGRANRIO, 2011), logo, este era o valor a ser superado, entendeu-se que se deveria estabelecer uma meta de $95 \%$ de acertos em sala de aula.

Disponível em: https://www.nucleodoconhecimento.com.br/engenharia-deproducao/projeto-petrobras 
iii. Brainstorming: reunião para geração de ideias e troca de conhecimento entre os participantes do projeto (SLACK et al, 2009).

iv. Projeto com ciclo de vida iterativo em que o planejamento ocorria de forma gradual, quer dizer, à medida que as atividades eram implementadas, uma nova etapa era planejada (PMI, 2017), em comum acordo com os alunos, vide Figura 2.

Figura 2: Ciclo de Vida Iterativo

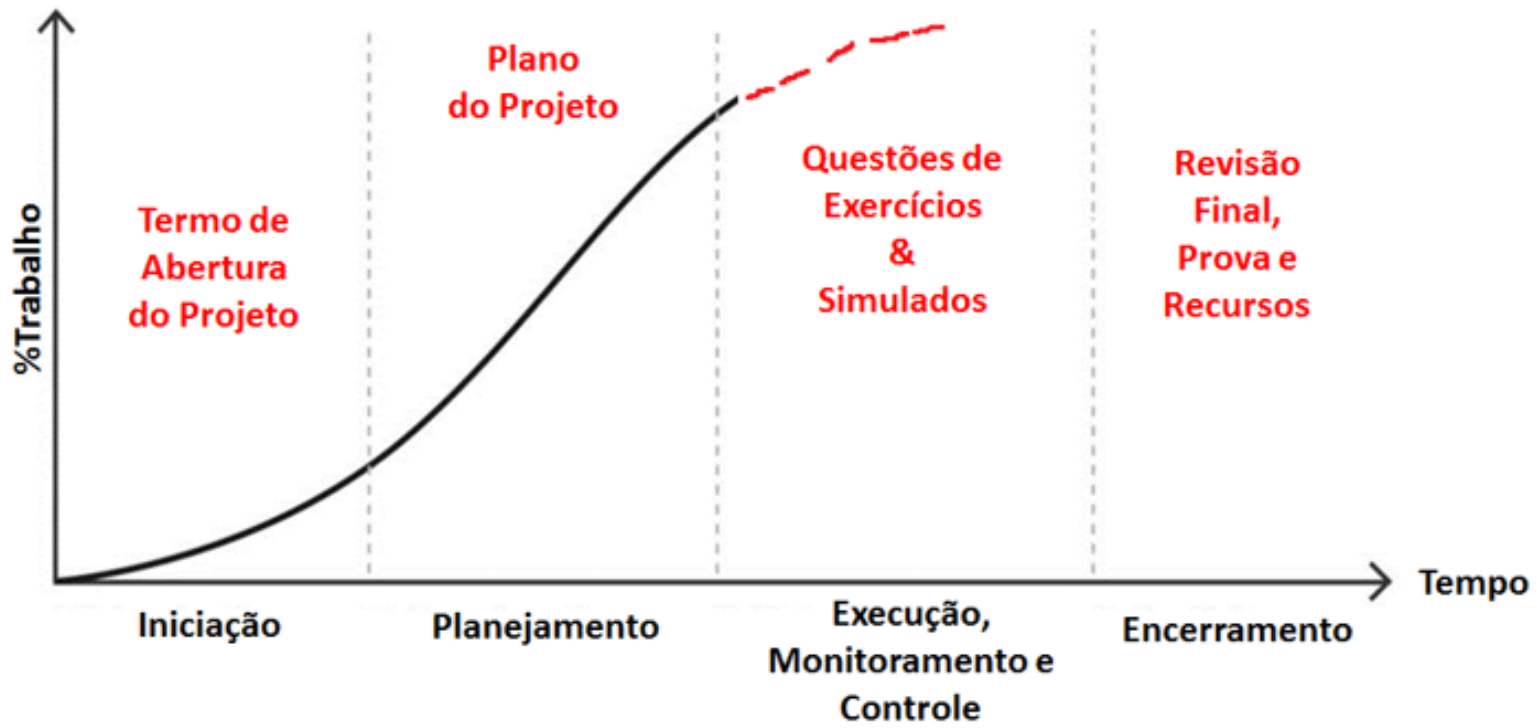

Fonte: Elaborado pelos autores (baseado no PMI, 2017)

Adotou-se esta ferramenta, porque:

Em projetos de ciclo de vida iterativo, será desenvolvida uma visão de alto nível para o projeto em geral, mas o escopo detalhado é determinado em uma iteração de cada vez e o planejamento detalhado para a iteração seguinte é executado à medida que o trabalho no escopo do projeto e entregas atuais avança (PMI, 2017, p. 151).

Então, como o projeto foi se desenvolvendo no ritmo imposto de acordo com a evolução dos alunos, esta ferramenta mostrou-se a mais apropriada. A lembrar que:

(...) um projeto é um esforço temporário realizado para criar um produto ou serviço único, diferente, de alguma maneira, de todos os outros produtos e serviços, com início e fim definidos, que utiliza

Disponível em: https://www.nucleodoconhecimento.com.br/engenharia-de- 
recursos, é dirigido por pessoas e obedece a parâmetros de custo, tempo e qualidade - (DINSMORE e SILVEIRA NETO, 2004, p. 1).

Como um preparatório para concursos públicos tem um prazo estabelecido, um objetivo a ser alcançado e recursos preestabelecidos optou-se por aplicar as técnicas de gerenciamento de projetos ao mesmo.

v. Constructo: "conceito ou construção teórica, puramente mental, elaborada ou sintetizada com base em dados simples, a partir de fenômenos observáveis, que auxilia os pesquisadores a analisar e entender algum aspecto de um estudo ou ciência" (MICHAELIS, 2021), vide Figura 3:

Figura 3: Constructo de Efetividade

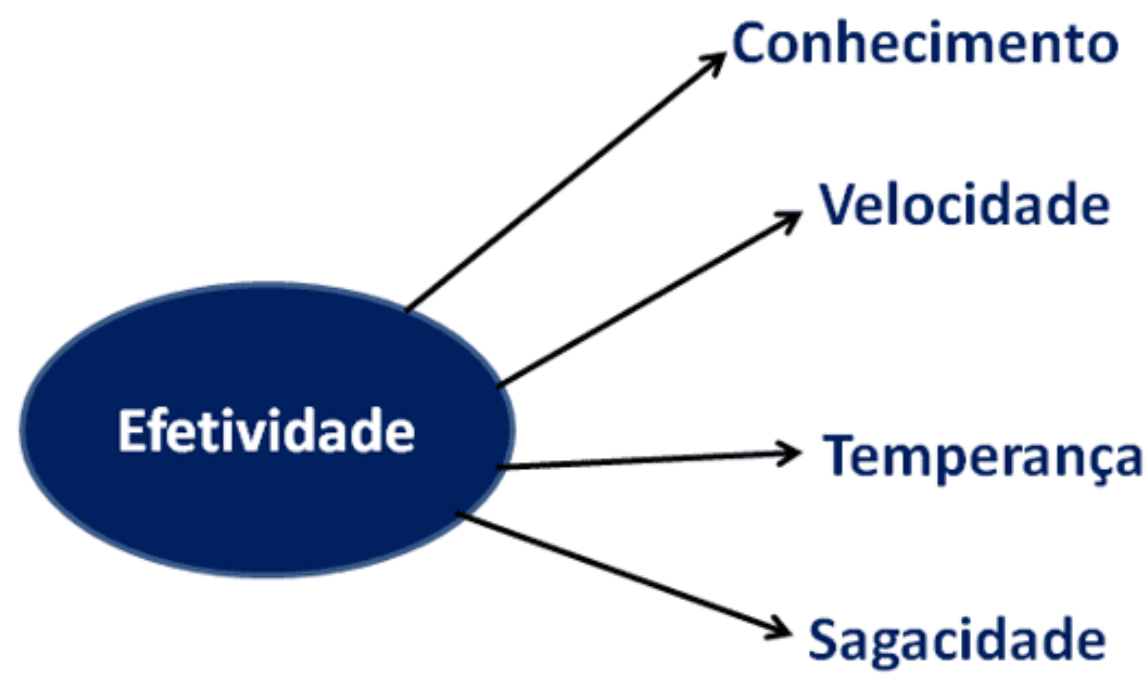

Fonte: Elaborado pelos autores (baseado em FEIST, FEIST e ROBERTS, 2015)

Os principais elementos escolhidos para a construção do constructo foram:

. Conhecimento para resolver as questões e não ficar em dúvida;

. Velocidade para resolver a prova no tempo estabelecido;

. Temperança para manter a calma na hora da prova;

Disponível em: https://www.nucleodoconhecimento.com.br/engenharia-deproducao/projeto-petrobras 
. Sagacidade para reconhecer as questões ambíguas.

vi. Indicadores-chave de desempenho para acompanhar o progresso dos alunos, os dados das aulas eram inseridos em uma planilha eletrônica, dentre os indicadores existentes, foram escolhidos: eficiência, eficácia e efetividade, porque eram simples de serem implementados.

vii. Planilha eletrônica para acompanhar o desempenho dos alunos (frequência às aulas, quantidade de exercícios, erros e acertos), no presente estudo, foi utilizado o programa Microsoft Excel pela facilidade de uso.

\subsection{UNIVERSO DA PESQUISA}

Um grupo de 15 alunos remanescentes dos concursos anteriores, isto é, aqueles que não haviam sido aprovados nos concursos da Petrobras, da Casa da Moeda, Marinha do Brasil, dentre outros, foram escolhidos para o Projeto Petrobras 2011.1.

Estes alunos foram escolhidos devido ao conhecimento prévio adquirido em mais de seis meses de estudo, ao senso de pertencimento ("camaradagem") e por estarem na mesma situação: "não aprovados" em concursos anteriores.

\subsection{FORMA DE REALIZAÇÃO}

O modelo transacional de liderança, segundo Wagner e Hollenbeck (2009, p.245), é composto de três elementos: líder, seguidores e situação. Logo, escolheu-se uma aluna (Sra. Rafaela) para liderar esse pequeno grupo, devido ao alto grau de conhecimento, entretanto, com baixo grau de rapidez. Essa situação trouxe a ela a responsabilidade de se adequar ao tempo de prova, ganhando rapidez, pois o projeto tinha prazo definido para ser finalizado, ou seja, na véspera da prova em questão.

Era uma situação "sui generis", isto é, sem igual, porque ao mesmo tempo em que a aluna Rafaela era a cliente, ela era também a "líder" do projeto (benchmark - 
referência), numa abordagem altamente customizada e interativa ("faça você mesmo").

A partir da construção de uma Estrutura Analítica de Projeto, definido pelo PMBOK (2017, p. 702) como "decomposição hierárquica do escopo total do trabalho a ser executado pela equipe do projeto a fim de alcançar os objetivos do projeto e criar as entregas exigidas", as disciplinas foram agrupadas pela professora orientadora, conforme pode ser verificado na Figura 4.

Figura 4: EAP do Projeto Petrobras 2011.1

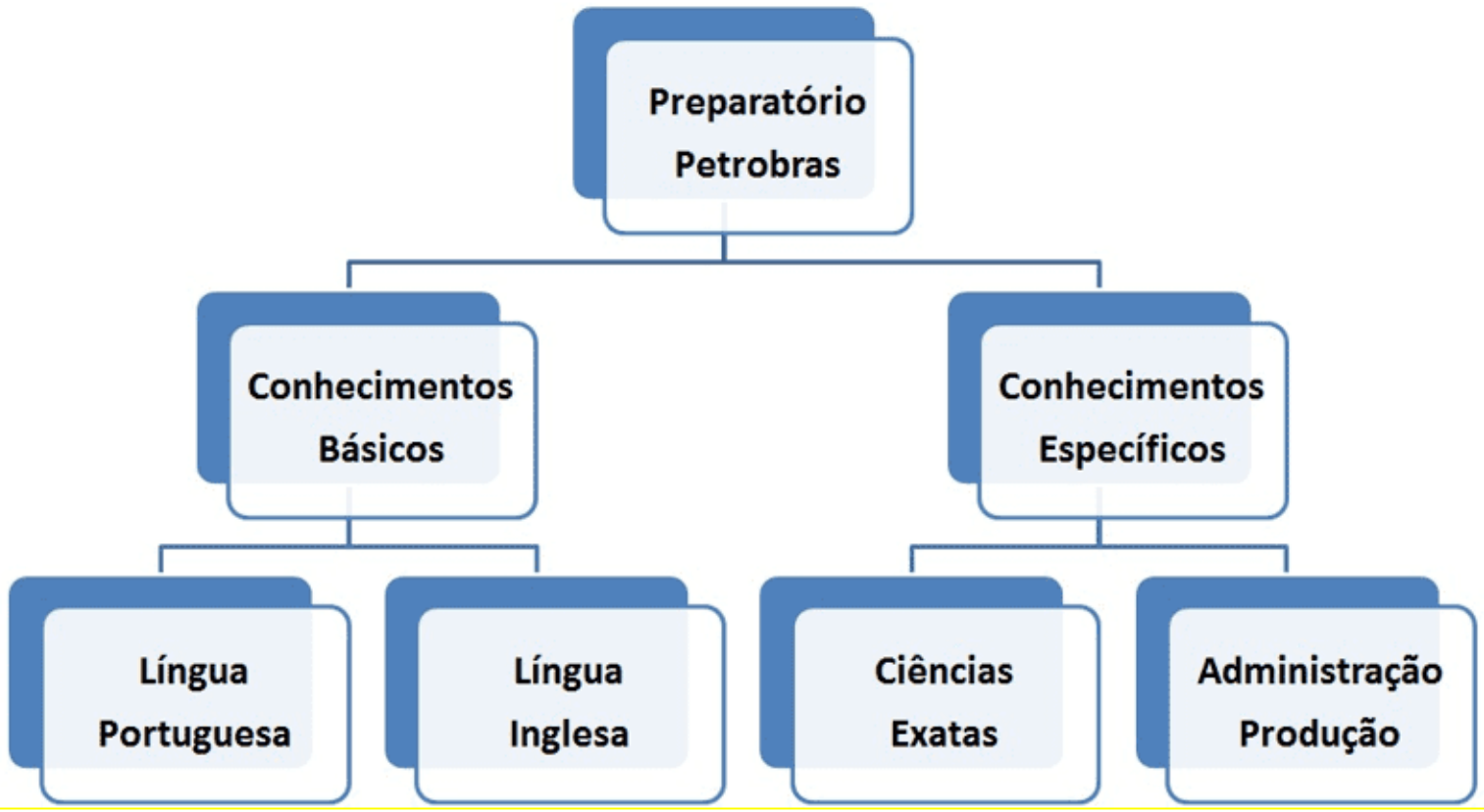

Fonte: Elaborado pelos autores (baseado no PMI, 2017)

A realização seguiu um diagrama de rede, definido pelo $\operatorname{PMBOK}$ (2017, p. 706) como: "qualquer demonstração esquemática dos relacionamentos lógicos entre as atividades do cronograma do projeto" -com retroalimentação, vide Figura 5.

Disponível em: https://www.nucleodoconhecimento.com.br/engenharia-deproducao/projeto-petrobras 
Fig.5: Diagrama de Rede com Retroalimentação/Feedback

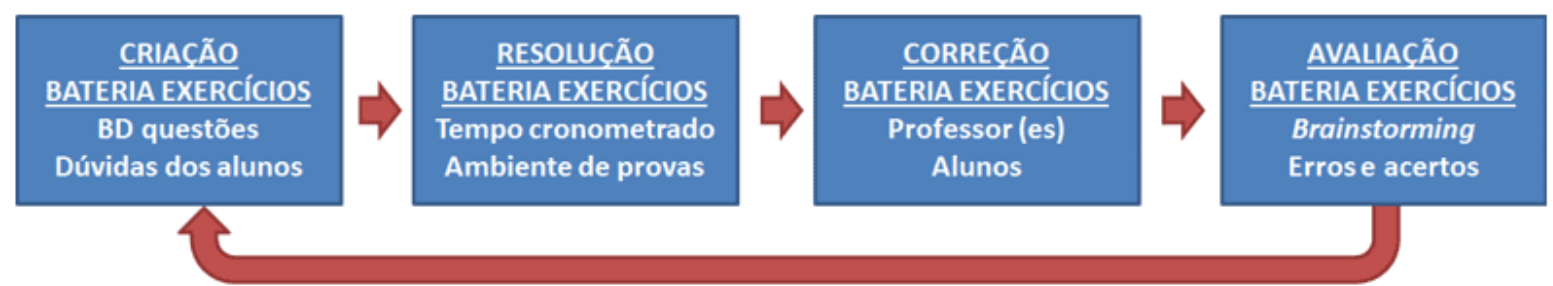

Retroalimentação/Feedback

Fonte: Elaborado pelos autores (baseado no PMI, 2017)

A partir da criação da bateria de exercícios, aplicavam-se os exercícios pertinentes às matérias exigidas pelo respectivo edital. Os alunos ficavam sozinhos em sala de aula e um despertador era colocado para a marcação do tempo desse exercício. Aqueles que iniciavam conversas eram silenciados pelos próprios colegas. Ao término do tempo estabelecido, os cartões-resposta eram coletados e corrigiam-se as questões com a participação dos alunos, item por item, repassando a respectiva teoria durante a correção.

Em seguida, fazia-se uma discussão (brainstorming) para se entender os erros e os acertos (o que os levaram a responder determinado item) e, a partir dessa análise, elaborava-se um pequeno resumo ou dicas que eram repassadas para os demais alunos que subsidiavam a escolha de novos exercícios.

\subsection{TRATAMENTO DAS INFORMAÇÕES}

A partir do banco de dados, era aplicada, a cada aula, uma bateria de exercícios correlatos (ex.: Produção com Sistemas de Informações ou Qualidade com Manutenção) em um determinado tempo. Após esse tempo, anotava-se a quantidade de questões respondidas (eficiência), a quantidade de questões certas (eficácia) e o grau de participação dos alunos (efetividade).

Gradativamente, o nível de cobrança aumentava, bem como a quantidade de questões e o grau de dificuldade, vide Figura 2.

Disponível em: https://www.nucleodoconhecimento.com.br/engenharia-deproducao/projeto-petrobras 
Figura 6: Relação de Quantidade e Qualidade das Questões

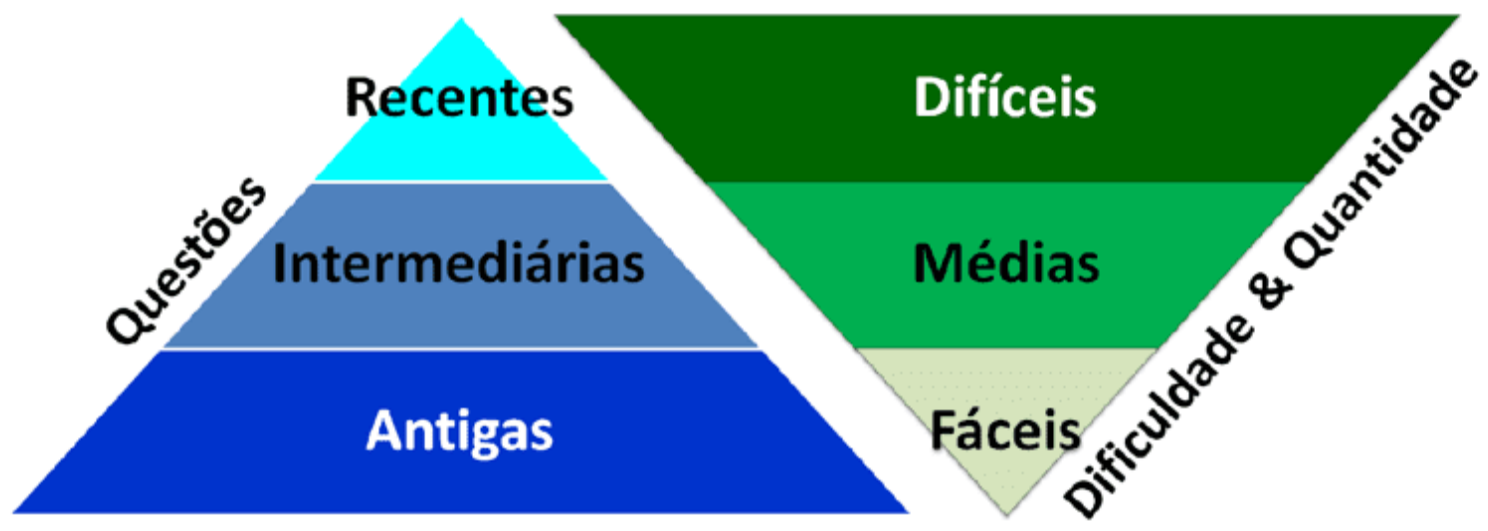

Fonte: Elaborado pelos autores (2021)

Ao corrigir as questões, o grupo era estimulado a mostrar os diferentes pontos de vista e estas informações eram armazenadas e repassadas para os demais alunos, por meio de pequenos resumos ou dicas de aula.

\section{ABORDAGEM CONCEITUAL}

Como tema central deste artigo estão os indicadores-chave de desempenho (KPI), logo, faz-se necessário explicitá-los.

Indicadores de desempenho, segundo Araújo (2009, p. 30): “(...) refere-se a parâmetros e critérios direcionados às avaliações que permitem confirmar evolução e realização de atividades ou de processos da organização ou, especificamente, de um dado negócio". Os indicadores utilizados neste trabalho são a eficiência, a eficácia e a efetividade.

\subsection{EFICIÊNCIA, EFICÁCIA E EFETIVIDADE}

a) Eficiência é "a palavra usada para indicar que a organização utiliza produtivamente, ou de maneira econômica os seus recursos" (MAXIMIANO, 2007, p. $5)$. 
b) Eficácia é "a palavra usada para indicar que a organização realiza seus objetivos" (MAXIMIAMO, 2007, p. 5).

c.1. Efetividade é definido primeiramente por Drucker, primeiro autor a separar os conceitos de eficiência e de eficácia, de acordo com Chiavenato:

A ênfase em fazer corretamente o trabalho (the best way de Taylor) para alcançar a eficiência passou à ênfase em fazer o trabalho mais relevante aos objetivos da organização para alcançar eficácia. (...) A Administração por Objetivos (APO) ou administração por resultados constitui o modelo administrativo identificado com o espírito pragmático e democrático da Teoria Neoclássica. Surgiu em 1954, quando Peter F. Drucker publicou um livro sobre a Administração por Objetivos, sendo considerado o pai da APO." (CHIAVENATO, 2014, p. 187-188).

c.2. Efetividade é a "relação entre resultados alcançados e os objetivos propostos ao longo do tempo." (OLIVEIRA, 2007, p. 467).

c.3. Efetividade para Paludo (2015):

(...) é o impacto final das ações, é o grau de satisfação das necessidades e dos desejos da sociedade pelos serviços prestados pela instituição. A efetividade vai além das entregas imediatas (metas) e analisa a transformação causada pela execução das ações. (PALUDO, 2015, p. 5)

c.4. Efetividade é "o critério de desempenho que mede a capacidade de a organização produzir a solução ou resposta desejada pelos participantes da comunidade." (SANDER, 1982, p. 13).

c.5. Efetividade quanto a Cury:

(...) termo usado para traduzir o comportamento gerencial quando, manipulado de forma adequada seus insumos (eficiência), o executivo atinge seus produtos (eficácia), com valor social, isto é, tendo tais produtos ampla aceitação do mercado. (CURY, 2006, p. 21).

Pode-se perceber que o assunto suscita discussões quanto aos conceitos por parte dos autores, no trabalho em questão, o conceito de eficiência está relacionado ao

Disponível em: https://www.nucleodoconhecimento.com.br/engenharia-deproducao/projeto-petrobras 
uso dos recursos, o de eficácia está relacionado aos resultados obtidos e o de efetividade relacionado à satisfação alcançada. Os três conceitos utilizados atendem plenamente às necessidades do projeto.

\section{ESTUDO CASO}

O Projeto Petrobras 2011.1 teve início com o lançamento do edital "PETROBRAS/PSP-RH-1/2011" no dia 30/06/2011 e duração prevista até o dia 27/08/2011, porque a prova seria realizada no dia 28/08/2011, portanto, 58 dias de duração (CESGRANRIO, 2011), vide Figura 6:

Figura 6: Lançamento do Edital Petrobras/PSP-RH-1/2011

\section{PETRÓLEO BRASILEIRO S.A. - PETROBRAS}

PROCESSO SELETIVO PÚBLICO PARA PREENCHIMENTO DE VAGAS E FORMAÇÃO DE CADASTRO RESERVA EM CARGOS DE NIVEL SUPERIOR E DE NIVEL MÉDIO

EDITAL N 1 - PETROBRAS/PSP-RH-1/2011, DE 30 DE JUNHO DE 2011

PETRÓLEO BRASILEIRO S.A. - PETROBRAS realizará Processo Seletivo Público para provimento de vagas e formação de cadastro, mediante condições estabelecidas neste Edital.

Fonte: Cesgranrio (2011)

O referido concurso oferecia 15 vagas na ampla concorrência para 6.554 candidatos o que perfaz uma relação de 436 candidatos/vaga, ou seja, uma concorrência muito elevada (CESGRANRIO, 2011).

O critério de desempate era maior pontuação: Bloco $1\left(1^{\circ}\right)$, Bloco $2\left(2^{\circ}\right)$, Conhecimentos Básicos (3ํ) e maior idade $\left(4^{\circ}\right)$, logo, fazer a prova de maneira correta era fundamental (CESGRANRIO, 2011).

As disciplinas do edital PSP RH-1/2011 foram:

LÍNGUA PORTUGUESA (10Q): 1. Compreensão e interpretação de textos. 2 Ortografia (nova ortografia, acentuação, emprego do hífen).

3. Morfologia (verbos irregulares, emprego das palavras "porque",

RC: 90617

Disponível em: https://www.nucleodoconhecimento.com.br/engenharia-deproducao/projeto-petrobras 
"por que", "por quê" e "porquê", "se" e quê",). 4. Sintaxe (regência verbal e nominal, concordância verbal, concordância nominal, emprego de verbos impessoais, indeterminação do sujeito, voz passiva pronominal, emprego de pronomes relativos, uso de "há" e "a", crase e colocação de pronomes átonos). (...) LíNGUA INGLESA (10Q): 1. Compreensão de texto escrito em língua inglesa 2. Itens gramaticais relevantes para a compreensão dos conteúdos semânticos. (...) BLOCO 1 (20Q): Gestão de Desempenho Organizacional. Administração Financeira. Gestão de Custos. Gestão de estoques. Gestão da Cadeia de Suprimentos. Projeto e Análise de Sistemas Logísticos. Modelagem e Simulação. Gerenciamento de Projetos. Probabilidade e Estatística. Planejamento e Controle da Produção. Gestão Ambiental. (...) BLOCO 2 (15Q): Engenharia de Métodos. Contabilidade Gerencial. Transporte e Distribuição Física. Responsabilidade Social. Previsão de Demanda. Planejamento das Instalações. Gestão de Sistemas de Produção e Operações. Planejamento Estratégico. Planejamento e Controle da Qualidade. Gestão Econômica. (...) BLOCO 3 (15Q): Ergonomia. Projeto e Organização do trabalho. Projeto de Fábrica e de Instalações Industriais: Layout/arranjo físico. Planejamento de Capacidade Processos Produtivos Discretos e Contínuos: procedimentos. Confiabilidade de Processos e Produtos. Programação Matemática. Engenharia do Produto. Gestão da Manutenção. Gestão da Tecnologia e Inovação. Processos Decisórios. Gestão de Sistemas da Qualidade. Desenvolvimento Sustentável. Gestão de Riscos em Análise de Investimentos (CESGRANRIO, 2011).

As disciplinas lecionadas no curso durante o projeto foram:

- $\underline{\text { BLOCO } 1}$ (20 questões):

. DES: Gestão de Desempenho Organizacional (ADG).

. MAT: Gestão de estoques. (APO)

. LOG: Gestão da Cadeia de Suprimentos (APO).

. LOG: Projeto e Análise de Sistemas Logísticos (APO).

. GPROJ: Gerenciamento de Projetos (APO).

. PCP: Planejamento e Controle da Produção (APO).

. RSA: Gestão Ambiental (GRS).

Disponível em: https://www.nucleodoconhecimento.com.br/engenharia-deproducao/projeto-petrobras 
- BLOCO 2 (15 questões):

. PTRAB: Engenharia de Métodos (APO).

. LOG: Transporte e Distribuição Física (APO).

. RSE: Responsabilidade Social (GRS).

. MAT: Previsão de Demanda (APO).

. PI\&LI: Planejamento das Instalações (APO).

. PCP: Gestão de Sistemas de Produção e Operações (APO).

. PE: Planejamento Estratégico (PEST).

. QLDE: Planejamento e Controle da Qualidade (APO).

- BLOCO 3 (15 questões):

. ERGO: Ergonomia. (GRS)

. PTRAB: Projeto e Organização do trabalho. (ADG)

. PI\&LI: Projeto de Fábrica e de Instalações Industriais: Layout/arranjo físico. (APO)

. PI\&LI: Planejamento de Capacidade Processos Produtivos Discretos e Contínuos: procedimentos (APO).

. MAN: Confiabilidade de Processos e Produtos. (APO)

. PPROD: Engenharia do Produto (APO).

. MAN: Gestão da Manutenção (APO).

. INOV: Gestão da Tecnologia e Inovação (APO). 
. DEC: Processos Decisórios (PEST).

. QLDE: Gestão de Sistemas da Qualidade (APO).

. RSA: Desenvolvimento Sustentável (GRS).

A partir de um pequeno grupo de 15 pessoas, liderados pela aluna Rafaela, foram aplicadas 690 questões de Administração da Produção, Planejamento Estratégico, Administração Geral e Gestão de Pessoas e Responsabilidade Socioambiental, por meio de baterias semanais de exercícios (CESGRANRIO, 2011), além das baterias de exercícios das outras disciplinas (língua portuguesa, língua inglesa, probabilidade, estatística, contabilidade e pesquisa operacional). As questões das matérias-alvo do projeto foram construídas e propostas com o desenrolar das aulas (planejamento iterativo) e contou com a colaboração dos alunos e ex-alunos do curso.

Além da turma-piloto, havia uma turma noturna com aulas aos finais de semana também, inclusive, aos domingos, aulas das $9 \mathrm{~h}$ às $18 \mathrm{~h}$, enquanto as aulas noturnas das 18:30 h às $22 \mathrm{~h}$. O trabalho foi realizado por meio de uma equipe coesa, professores e alunos trabalhando juntos e nenhum item do planejamento foi relegado a segundo plano. O edital foi seguido precisamente, os alunos contribuíram indicando questões diversas para serem resolvidas e ocorreu um vasto compartilhamento de informações.

\section{ANÁLISE DOS RESULTADOS}

A análise dos resultados e as medidas aplicadas a partir dessa análise são norteadas pelo indicador geral de eficácia (acertos) dos alunos que participaram do projeto. O período de acompanhamento desses alunos em relação a evolução nas resoluções de questões durou, aproximadamente, 8 (oito) semanas, sendo representado na tabela abaixo (Tabela 1) por S1, S2, S3, S4, S5, S6, S7 e S8. Além disso, houve uma progressão no número de questões realizadas a cada semana, conforme os alunos se adequavam ao ritmo exigido pelo projeto, representada pelo

Disponível em: https://www.nucleodoconhecimento.com.br/engenharia-deproducao/projeto-petrobras 
número de questões resolvidas, na semana, acompanhada da letra "q", por exemplo, "70q" significa que, naquela semana, 70 (setenta) questões foram resolvidas pelos alunos.

Tabela 1: Eficácia dos alunos do Projeto Petrobras 2011.1

\begin{tabular}{|l|r|r|r|r|r|r|r|r|}
\multicolumn{1}{|c|}{ ALUNOS } & \multicolumn{1}{c}{ S1: 70q } & \multicolumn{1}{c}{ S2: 75q } & \multicolumn{1}{c}{ S3: 80q } & \multicolumn{1}{c|}{ S4: 85q } & \multicolumn{1}{c|}{ S5: 90q } & \multicolumn{1}{c|}{ S6q } & \multicolumn{1}{c|}{ S7: 95q } & S8: 100q \\
\hline Alessandra & $60,0 \%$ & $53,3 \%$ & $56,3 \%$ & $49,4 \%$ & $46,7 \%$ & $64,2 \%$ & $75,8 \%$ & $80,0 \%$ \\
\hline André & $62,9 \%$ & $57,3 \%$ & $58,8 \%$ & $58,8 \%$ & $57,8 \%$ & $74,7 \%$ & $78,9 \%$ & $84,0 \%$ \\
\hline Andreia & $58,6 \%$ & $53,3 \%$ & $52,5 \%$ & $52,9 \%$ & $51,1 \%$ & $71,6 \%$ & $75,8 \%$ & $79,0 \%$ \\
\hline Bruno & $42,9 \%$ & $41,3 \%$ & $43,8 \%$ & $47,1 \%$ & $50,0 \%$ & $63,2 \%$ & $74,7 \%$ & $75,0 \%$ \\
\hline Gisele & $61,4 \%$ & $56,0 \%$ & $57,5 \%$ & $57,6 \%$ & $53,3 \%$ & $65,3 \%$ & $75,8 \%$ & $78,0 \%$ \\
\hline Letícia & $57,1 \%$ & $57,3 \%$ & $56,3 \%$ & $60,0 \%$ & $55,6 \%$ & $70,5 \%$ & $74,7 \%$ & $77,0 \%$ \\
\hline Luciana & $61,4 \%$ & $60,0 \%$ & $60,0 \%$ & $61,2 \%$ & $53,3 \%$ & $69,5 \%$ & $77,9 \%$ & $79,0 \%$ \\
\hline Marcelo & $62,9 \%$ & $61,3 \%$ & $61,3 \%$ & $51,8 \%$ & $63,3 \%$ & $78,9 \%$ & $85,3 \%$ & $84,0 \%$ \\
\hline Marcelo2 & $57,1 \%$ & $62,7 \%$ & $60,0 \%$ & $62,4 \%$ & $60,0 \%$ & $77,9 \%$ & $83,2 \%$ & $83,0 \%$ \\
\hline Natália & $61,4 \%$ & $64,0 \%$ & $62,5 \%$ & $65,9 \%$ & $64,4 \%$ & $83,2 \%$ & $86,3 \%$ & $85,0 \%$ \\
\hline Nathalie & $64,3 \%$ & $58,7 \%$ & $57,5 \%$ & $63,5 \%$ & $63,3 \%$ & $82,1 \%$ & $85,3 \%$ & $84,0 \%$ \\
\hline Rafael & $57,1 \%$ & $61,3 \%$ & $55,0 \%$ & $58,8 \%$ & $62,2 \%$ & $71,6 \%$ & $81,1 \%$ & $80,0 \%$ \\
\hline Rafaela & $60,0 \%$ & $60,0 \%$ & $60,0 \%$ & $62,4 \%$ & $64,4 \%$ & $78,9 \%$ & $85,3 \%$ & $85,0 \%$ \\
\hline Rodrigo & $54,3 \%$ & $52,0 \%$ & $52,5 \%$ & $52,9 \%$ & $52,2 \%$ & $63,2 \%$ & $75,8 \%$ & $79,0 \%$ \\
\hline Simone & $52,9 \%$ & $54,7 \%$ & $53,8 \%$ & $56,5 \%$ & $44,4 \%$ & $61,1 \%$ & $75,8 \%$ & $81,0 \%$ \\
\hline
\end{tabular}

Fonte: Elaborado pelos autores (2021)

Pode-se observar, na tabela acima, que os alunos evoluíram ao longo das 8 (oito) semanas de aula. O gráfico abaixo (Gráfico 1) ratifica esta informação e destaca o desempenho da aluna Rafaela: 
Gráfico 1: Eficácia dos alunos ao longo do tempo

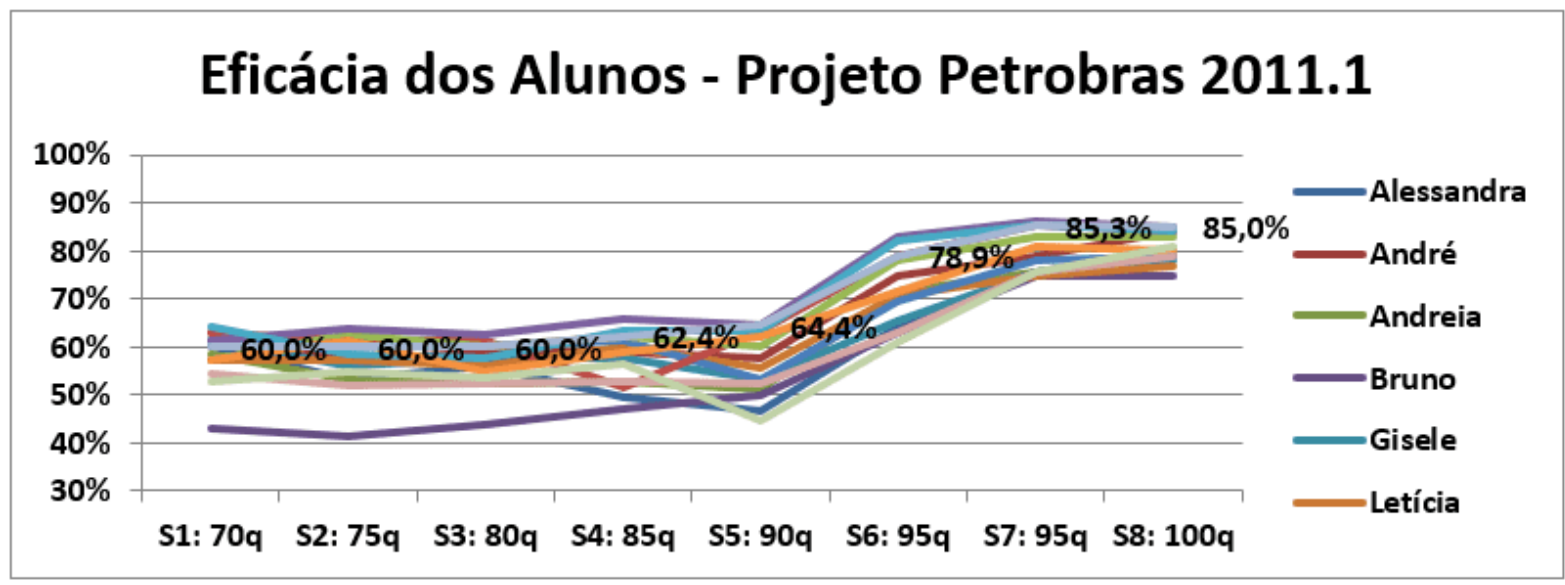

Fonte: Elaborado pelos autores (2021)

A partir da análise geral, cada aluno teve a sua eficiência medida, ou seja, foi observada a evolução dos alunos em cada área, conforme o fechamento da semana, e aplicada medidas emergenciais corretivas nas áreas com os menores índices. O gráfico a seguir (Gráfico 2) ilustra a semana 1 da aluna Rafaela e a sua eficiência em relação as áreas medidas no projeto.

Gráfico 2: Eficiência da aluna Rafaela em cada área na semana 1 (S1)

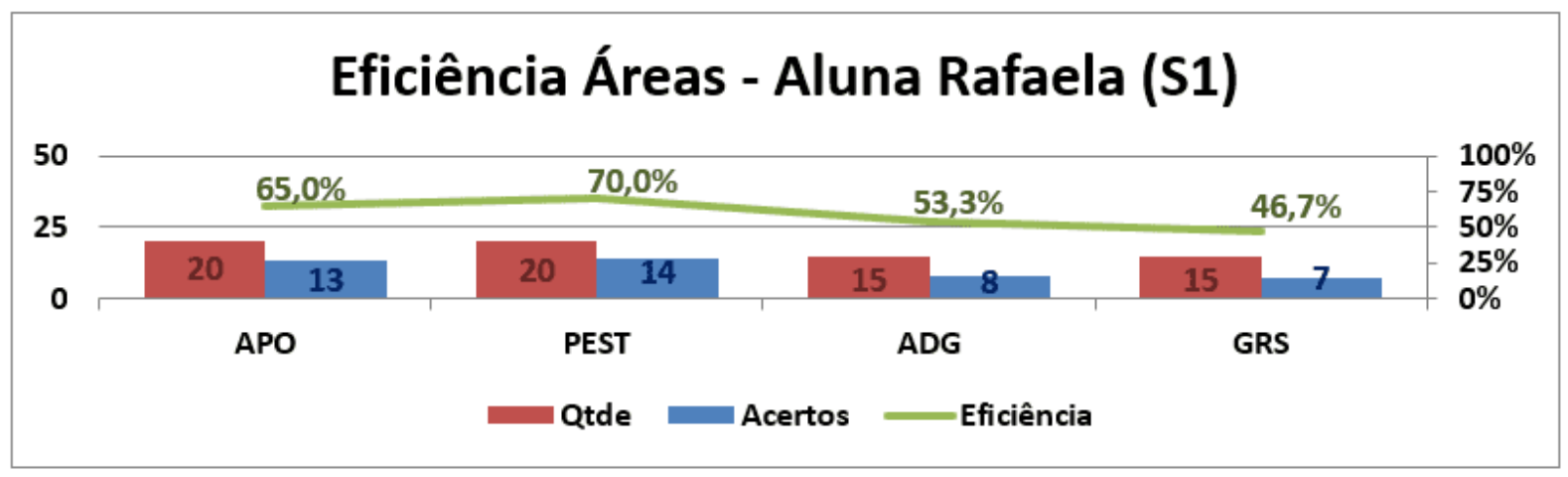

Fonte: Elaborado pelos autores (2021)

Após a análise gráfica, ao final da semana 1, percebeu-se que, em um primeiro momento, algumas medidas corretivas deveriam ser tomadas urgentemente nas áreas de Gestão de Pessoas e Responsabilidade Socioambiental (GRS) e

Disponível em: https://www.nucleodoconhecimento.com.br/engenharia-deproducao/projeto-petrobras 
Administração Geral (ADG). Algumas medidas tomadas foram: revisão da bibliografia proposta focada na disciplina específica relacionada às questões que tiveram mais erros; leituras complementares de outras bibliografias e materiais; resolução de mais questões, em sala de aula, relacionadas as mesmas disciplinas e áreas com maiores erros, entre outras.

Essa análise foi realizada repetidamente, a cada fechamento da semana, sempre usando o critério de melhorar o índice de eficiência com medidas corretivas aplicadas sobre as áreas com os piores desempenhos na semana, vide os gráficos das semanas seguintes abaixo (Gráfico 3, Gráfico 4, Gráfico 5, Gráfico 6, Gráfico 7, Gráfico 8, Gráfico 9).

Gráfico 3: Eficiência da aluna Rafaela em cada área na semana 2 (S2)

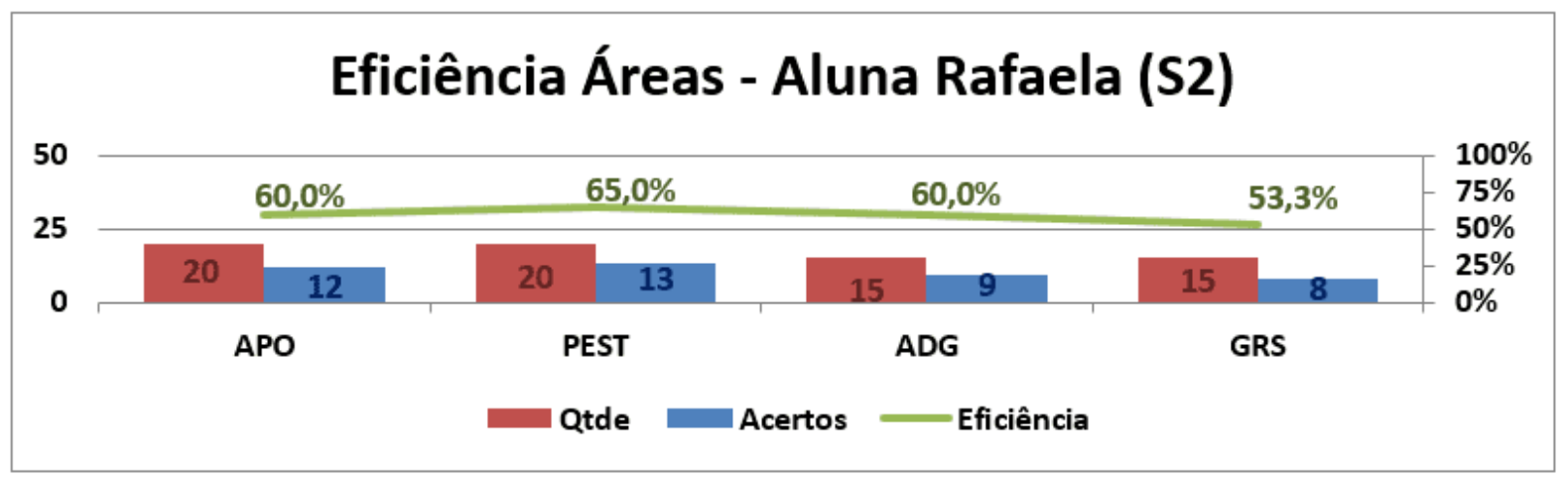

Fonte: Elaborado pelos autores (2021) 
Gráfico 4: Eficiência da aluna Rafaela em cada área na semana 3 (S3)

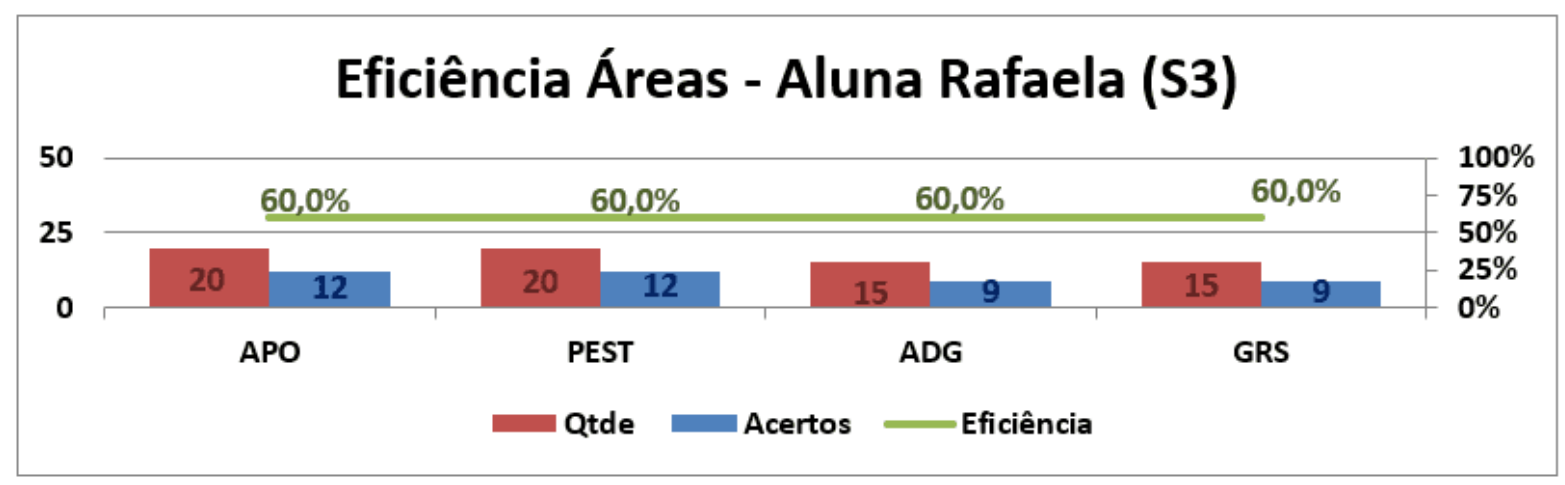

Fonte: Elaborado pelos autores (2021)

Gráfico 5: Eficiência da aluna Rafaela em cada área na semana 4 (S4)

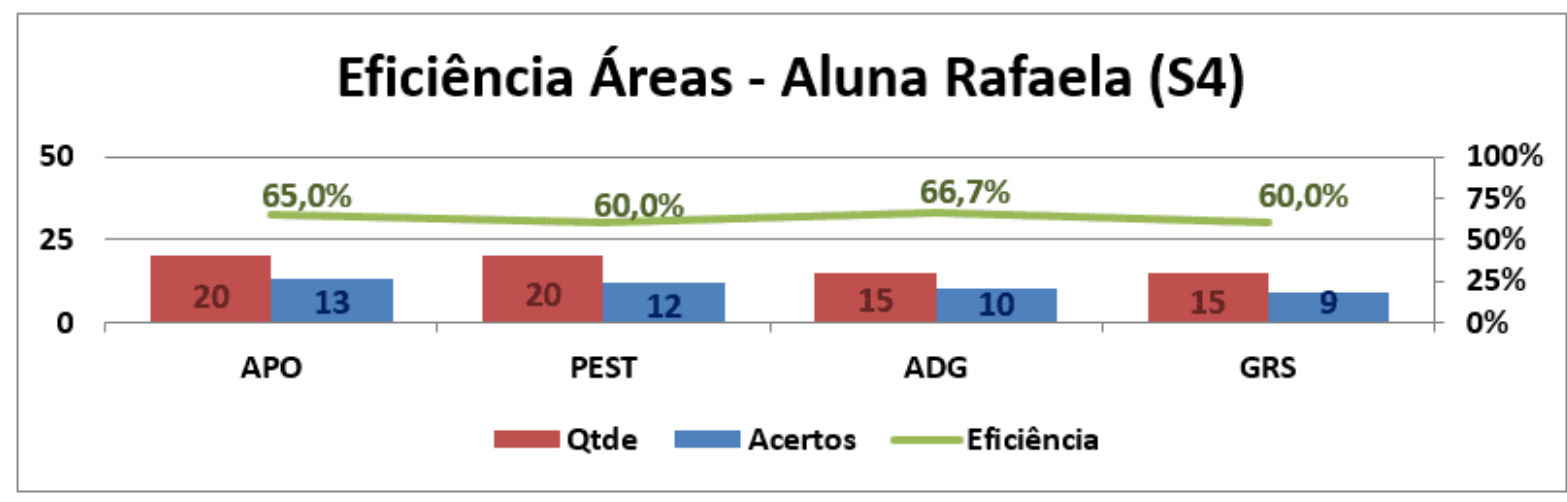

Fonte: Elaborado pelos autores (2021) 
Gráfico 6: Eficiência da aluna Rafaela em cada área na semana 5 (S5)

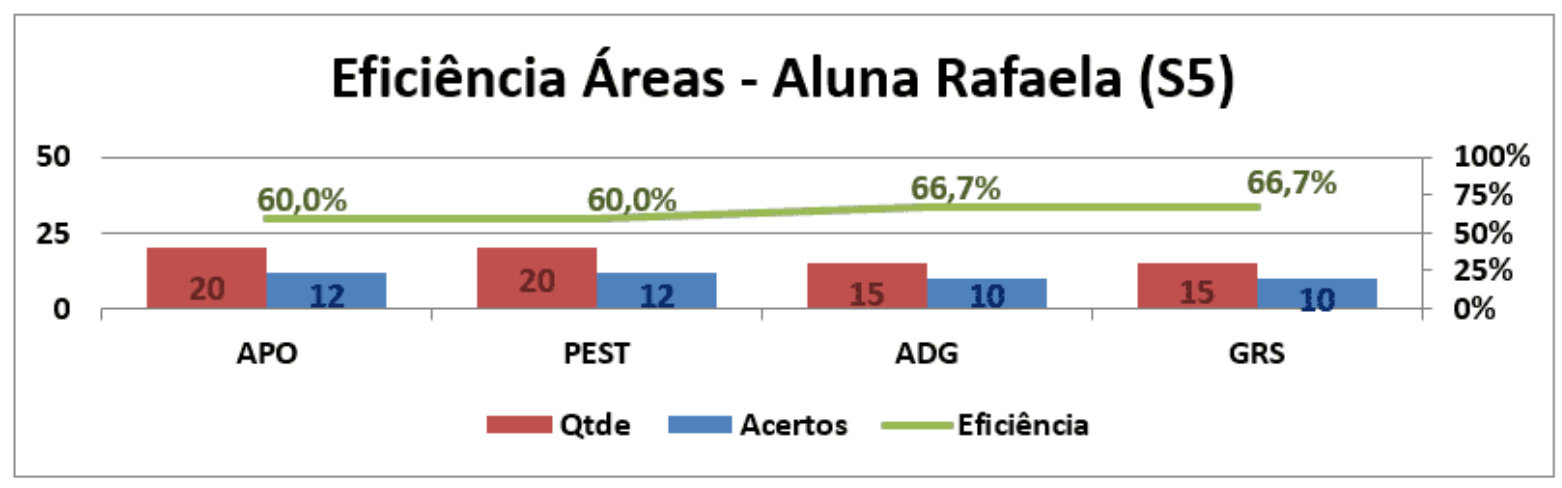

Fonte: Elaborado pelos autores (2021)

Gráfico 7: Eficiência da aluna Rafaela em cada área na semana 6 (S6)

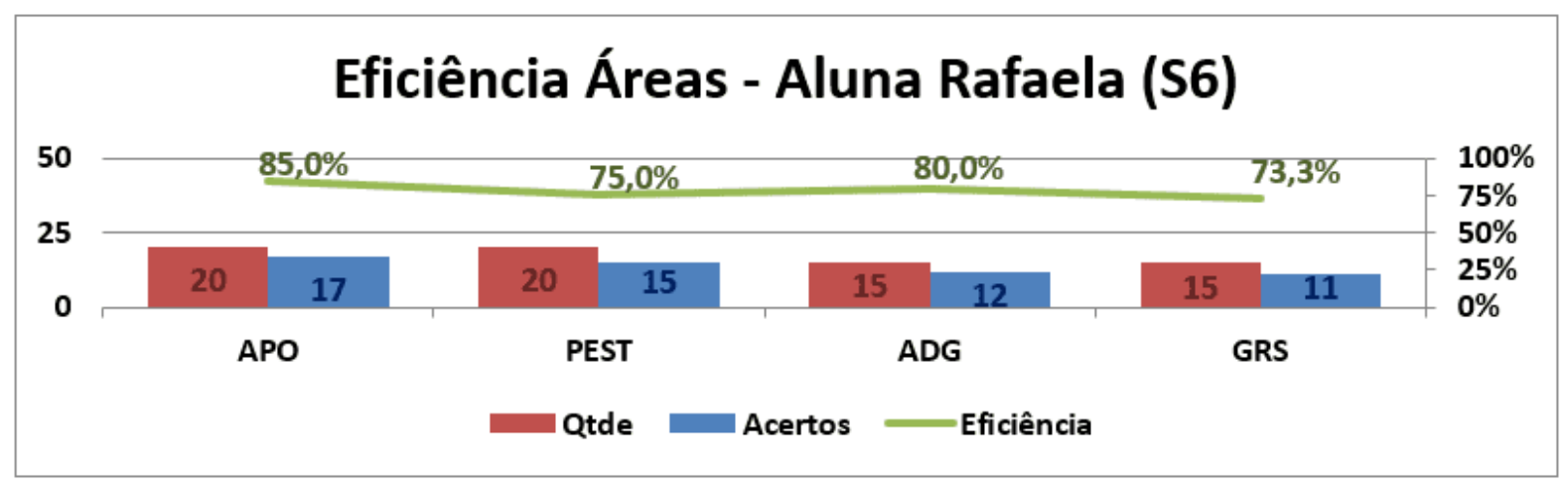

Fonte: Elaborado pelos autores (2021) 
Gráfico 8: Eficiência da aluna Rafaela em cada área na semana 7 (S7)

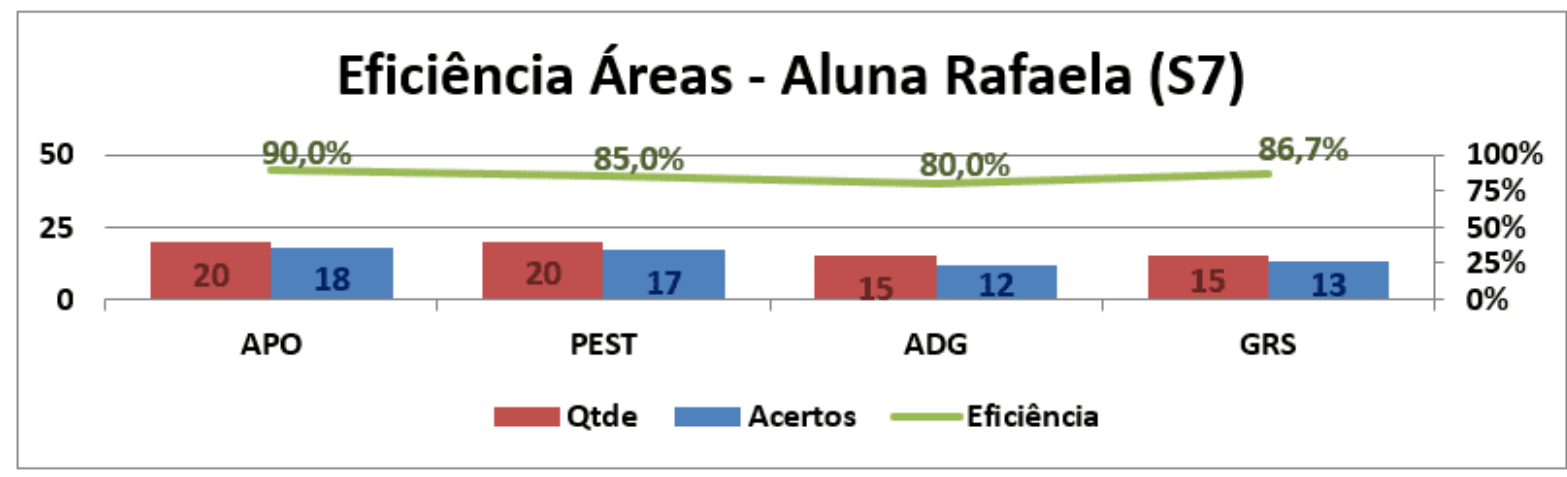

Fonte: Elaborado pelos autores (2021)

Gráfico 9: Eficiência da aluna Rafaela em cada área na semana 8 (S8)

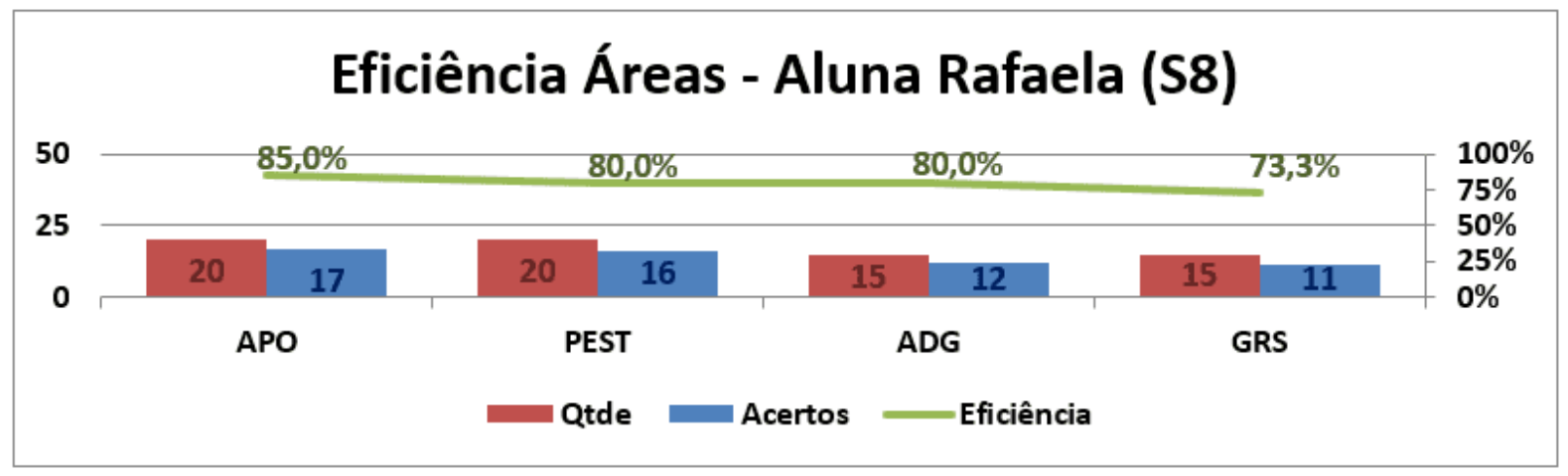

Fonte: Elaborado pelos autores (2021)

Em paralelo a esses indicadores, era monitorada a efetividade do projeto como um todo. Esse monitoramento uniu a eficácia com a eficiência, refletindo o atendimento da necessidade do projeto, que é a evolução qualitativa dos alunos e a aprovação no concurso em questão. 
Gráfico 10: Efetividade do projeto (eficácia + eficiência)

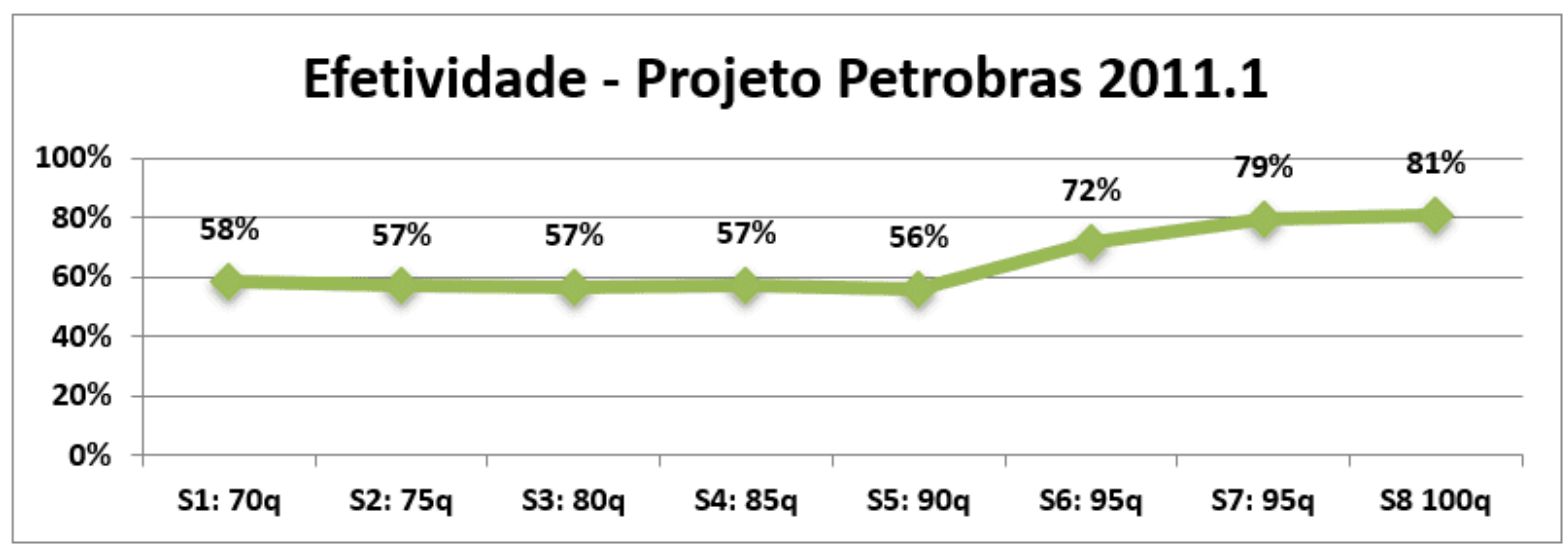

Fonte: Elaborado pelos autores (2021)

Conforme pode se verificar, na véspera da prova, ou seja, no final do projeto, a efetividade foi de $81 \%$, sendo significativa para aquilo que tinha sido proposto no seu início.

A Sra. Rafaela (líder da equipe) e outros 31 alunos foram aprovados e, hoje, trabalham numa das maiores empresas do País e da América Latina, a Petrobras (HIRATA e BULLA, 2021), vide Figura 7:

Figura 7: O nome da Sra. Rafaela publicado no Diário Oficial

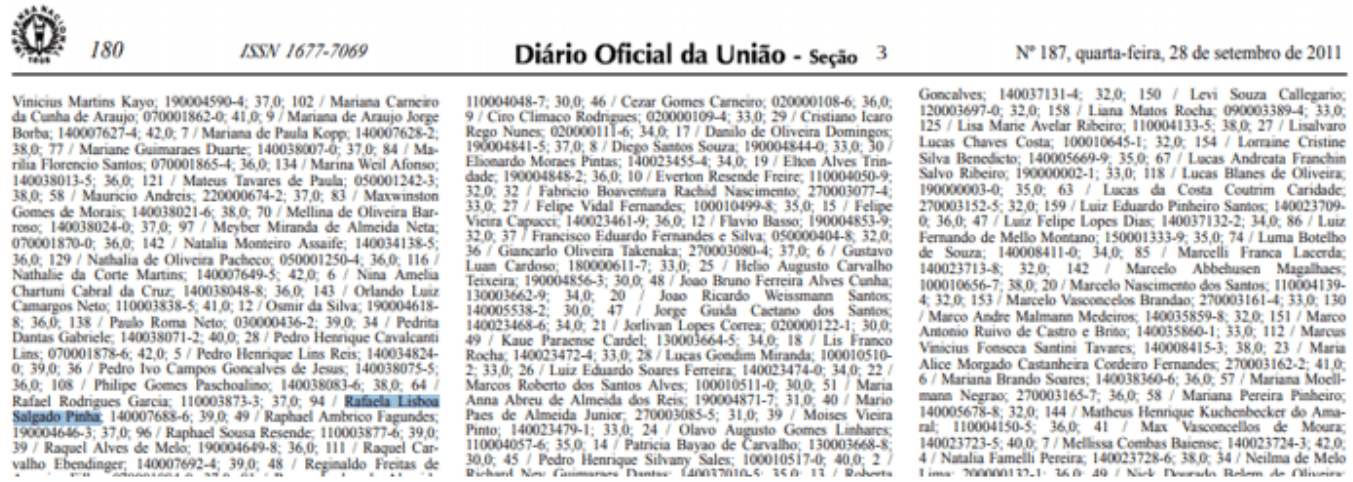

Fonte: Diário Oficial da União (2011)

Disponível em: https://www.nucleodoconhecimento.com.br/engenharia-deproducao/projeto-petrobras 
- Os resultados do Projeto Petrobras 2011.1 com os alunos aprovados foram:

. 2ำ lugar: Sr. André (Pessoas com Deficiência, PCD);

4ํlugar: Sra. Amaya (ampla concorrência);

- Total: 32 alunos que participaram das aulas do curso foram classificados no concurso, de um total de 150 (cento e cinquenta). Inicialmente, o edital contemplava 15 (quinze) vagas, porém foram convocados mais 135 (centro e trinta e cinco) candidatos do cadastro de reserva, inclusive a aluna Rafaela (CESGRANRIO, 2011).

Dentre os produtos resultantes do Projeto Petrobras 2011.1, além da preparação dos alunos, confeccionou-se a apostila TOP 600 Petrobras com 671 questões que serviu de base para outros preparatórios e uma nova metodologia de ensino. Observa-se então como a aplicação dos KPl's pode melhorar o ensino e o resultado dos alunos para lograr êxito em vagas de concursos públicos.

\section{CONSIDERAÇÕES FINAIS}

O presente artigo procurou responder de forma clara e objetiva como os indicadores de desempenho, bem como, as ferramentas de gestão podem ser usadas em um curso preparatório para concurso público.

Apesar de se entender que o número de vagas é muito menor que o número de candidatos, a satisfação do cliente refere-se ao desempenho do mesmo na prova, porque como o projeto é realizado de forma compartilhada, os alunos conhecem os aprovados e essa transparência é fundamental.

A escolha de um aluno para capitanear os demais alunos foi um marco e um balizador, porque serviu de benchmark para os demais alunos. Alunos que tiveram um excelente desempenho em sala de aula, por questões emocionais, não foram tão bem nas provas ou vice-versa, então, as situações vivenciadas durante o projeto serviram como aprendizado.

Disponível em: https://www.nucleodoconhecimento.com.br/engenharia-deproducao/projeto-petrobras 
O trabalho trouxe como fator de inovação a aplicação dos conceitos de KPI's na área da educação e ensino, especificamente no ensino focado em concursos públicos no Brasil. Nem todos os alunos conseguiram aprovação no concurso Petrobras 2011.1, mas aqueles que persistiram nos estudos estão, hoje, empregados na esfera pública, por exemplo, o Sr. Marcelo Salgueiro que participou do projeto e atualmente trabalha no Corpo de Engenheiros da Marinha do Brasil.

O trabalho em equipe e a utilização dos indicadores de desempenho ajudaram a controlar os resultados dos alunos e participantes do projeto e a agir sobre esses resultados, construindo um projeto vencedor. Para um trabalho futuro, é indicado que indicadores de desempenho de segunda geração sejam aplicados, pois os concursos públicos estão migrando para o ambiente virtual. Além disso, indica-se aplicar a metodologia a um maior número de alunos, a fim de se aumentar o espaço amostral a ser estudado, e consolidando os resultados alcançados.

\section{REFERÊNCIAS}

ARAÚJO, L. C. G. Organização, sistemas e métodos e as tecnologias de gestão organizacional: arquitetura organizacional, benchmarking, empowerment, gestão pela qualidade total, reengenharia. 4 ed. São Paulo: Atlas, 2009.

ASSOCIAÇÃO BRASILEIRA DE NORMAS TÉCNICAS. NBR 6022: artigo em publicação periódica científica impressa: apresentação. Rio de Janeiro, 2003.

CEBRASPE. Disponível em: https://www.cebraspe.org.br/

CESGRANRIO. Disponível em: https://www.cesgranrio.org.br

CHIAVENATO, I. Introdução à Teoria Geral da Administração. 3 ed. Rio de Janeiro: Elsevier, 2014.

CURY, A. Organização e métodos: uma visão holística. 8 ed. São Paulo: Atlas, 2006. 
DEMING, W. E. Qualidade: a revolução da administração. Rio de Janeiro: Saraiva, 2004.

DIÁRIO OFICIAL DA UNIÃO (DOU). Disponível em: https://www.e-diariooficial.com/

DINSMORE, P. C.; SILVEIRA NETO, F. H. Gerenciamento de Projetos: Como gerenciar seu projeto com qualidade, dentro do prazo e custos previstos. Rio de Janeiro: Qualitymark, 2004.

FEIST, J.; FEIST, G. J.; ROBERTS, T. Teorias da personalidade. 8. ed. Porto Alegre: AMGH, 2015.

FOLHA DIRIGIDA. Mercado de concursos em 2020: Segurança é destaque e online cresce, $2020 . \quad$ Disponível em: https://folhadirigida.com.br/concursos/noticias/mercado-concursos/mercado-deconcursos-publicos-no-brasil-2020. Acesso em: 30/05/2021.

HIRATA, L.; BULLA, Olívia. Vale é a empresa mais valiosa da América Latina e deixa Mercado Livre para trás, 2021. Disponível em: https://valorinveste.globo.com/mercados/rendavariavel/empresas/noticia/2021/04/27/vale-a-empresa-mais-valiosa-da-amrica-latinae-deixa-mercado-livre-para-trs.ghtml. Acesso em: 04/05/2021

IBGE. Disponível em: https://www.ibge.gov.br

MAXIMIANO, A. C. A. Introdução à Administração. 6. Ed. São Paulo: Atlas, 2007.

MICHAELIS. Moderno dicionário da língua portuguesa. São Paulo: Melhoramentos.

Disponível em: http://michaelis.uol.com.br/moderno/portugues/index.php. Acesso em: 04/05/2021

OLIVEIRA, D. P. R. de. Sistemas, Organização \& Métodos. 17 ed. São Paulo: Atlas, 2013. 
PALUDO, A. Administração Pública. 4 ed. Rio de Janeiro: Forense, 2015.

PMI. Project Management Institute. Guia PMBOK®: Um Guia do Conjunto de Conhecimentos em Gerenciamento de Projetos. 6 ed. EUA: Project Management Institute, Inc., 2017.

SANDER, B. Gestão da Educação na América Latina: construção e reconstrução do conhecimento. Campinas, SP: Autores Associados, 1982.

SLACK, N. et al. Administração da Produção. 3 ed. São Paulo: Atlas, 2009.

WAGNER, J. A.; HOLLENBECK, J. H. Comportamento Organizacional: criando vantagem competitiva. São Paulo: Saraiva, 2009.

YIN, R. K. Estudo de caso: planejamento e métodos. 3 ed. Porto Alegre: Bookman, 2005.

Enviado: Junho, 2021.

Aprovado: Julho, 2021. 